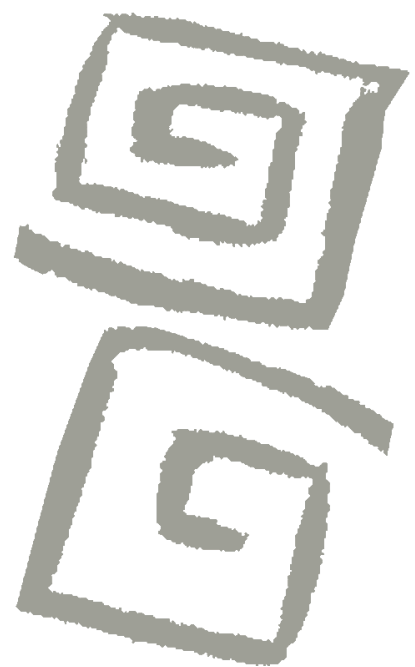

\title{
Reflexiones teóricas sobre sujetos de la praxis y sujetos de la antítesis para la Reforma Sanitaria Brasileña
}

\author{
Theoretical reflections regarding subjects of praxis \\ and subjects of antithesis in Brazilian health reform
}

Jairnilson Silva Paim ${ }^{1}$

'Médico, Doctor en Salud Pública. Profesor Titular, Instituto de Saúde Coletiva Universidade Federal de Bahia, Brasil. $\triangle$
RESUMEN La Reforma Sanitaria Brasileña ha sido reconocida como un proyecto que trasciende la dimensión sectorial al considerar el concepto ampliado de salud y de determinación social, que la distingue de las reformas de los sistemas de salud del siglo XX. Este artículo tiene como objetivo apoyar la construcción de los conceptos sujetos de la praxis y sujetos de la antítesis, para lo cual discute algunos de los retos de la praxis en la Reforma Sanitaria Brasileña, la constitución de sujetos sociales y la aparición de sujetos de la antítesis. Se argumenta que la reflexión teórica puede contribuir al análisis político en salud y vislumbrar el poder de una praxis que desequilibre el carácter conservador de la revolución pasiva.

PALABRAS CLAVES Teoría Social; Reforma Sanitaria; Sistemas de Salud; Brasil.

ABSTRACT The Brazilian Health Reform has been recognized as a project that transcends the sectoral dimension in that it considers an expanded concept of health and social determination, which distinguishes it from other health system reforms of the twentieth century. This article aims to contribute to the construction of the concepts subjects of praxis and subjects of antithesis by discussing certain challenges of praxis in the Brazilian Health Reform, the constitution of social subjects and the emergence of subjects of antithesis. The article argues that theoretical reflection can contribute to political analysis in health and discern the power of a praxis that destabilizes the conservative character of the passive revolution.

KEY WORDS Social Theory; Health Care Reform; Health Systems; Brazil. 


\section{INTRODUCCIÓN}

En la bibliografía internacional se observan estudios sobre reformas de sistemas de $\operatorname{salud}^{(1,2,3)}$, sobre todo a partir de la década de 1980, muchas de las cuales han sido promovidas por organismos internacionales como el Banco Mundial. Aunque la expresión "reforma sanitaria"(4) sea utilizada en algunas referencias bibliográficas, hay evidencias de que la Reforma Sanitaria Brasileña fue más allá de la dimensión sectorial, al considerar el concepto ampliado de salud, a partir de su determinación social. En este sentido, se distingue de las reformas sectoriales que ocurrieron en varias partes del mundo a lo largo del siglo $X X^{(5)}$.

En un trabajo previo $^{(5)}$, la Reforma Sanitaria Brasileña se analizó considerando distintos momentos: idea, movimiento, propuesta, proyecto y proceso. Antes de la configuración de la propuesta se difundió la idea. Del mismo modo, la transformación de la propuesta en proyecto y proceso ocurrió en presencia del movimiento. Este ciclo ideapropuesta-proyecto-movimiento-proceso fue concebido a partir de momentos dialécticamente imbricados: el movimiento generaba la propuesta y el proyecto desencadenaba el proceso, que condicionaba el propio movimiento. En una situación dada el proyecto podía superponerse al movimiento y, en otra, el proceso podía ser dominante con relación al proyecto.

En lo que respecta a la Reforma Sanitaria Brasileña, algunos de sus formuladores admitían que el proyecto podía participar en la construcción de una "democracia progresiva" con vistas al socialismo ${ }^{(6)} \mathrm{O}$ incluso diseñar estrategias y tácticas consistentes con su carácter revolucionario ${ }^{(7)}$. Las "hipótesis explicativas" formuladas en el período ${ }^{(8)}$, que apuntaban a la construcción de viabilidad del proyecto y a la ampliación de la democracia política, no parecían indicar que el movimiento sanitario actuaría en los límites de una revolución pasiva ${ }^{(9)}$. Sin embargo, las características del desarrollo histórico de la sociedad brasileña así como la acción política de los actores sociales dosificaron los ritmos y los contenidos del proceso de la Reforma Sanitaria Brasileña, ilustrando algunas de las posibilidades de la revolución pasiva y del transformismo ${ }^{(5)}$.

El presente artículo pretende explorar la noción de "portadores de la antítesis"(10), a partir de fundamentar la construcción de los conceptos de sujetos de la praxis y sujetos de la antítesis para el movimiento de la Reforma Sanitaria Brasileña. Comienza con una breve revisión del concepto de praxis y su articulación con la dialéctica; luego, se presenta una tipología que señala sus conexiones con la Reforma Sanitaria Brasileña, así como la necesidad de un trabajo teórico para la elaboración del concepto de sujetos de la antítesis; finalmente, se discuten ciertos desafíos de la praxis y la pertinencia de considerar la emergencia de sujetos de la antítesis en su proceso.

\section{REVISANDO LOS CONCEPTOS DE PRAXIS Y DE DIALÉCTICA}

Las palabras "práctica" y "praxis" se refieren a la acción. La primera ha sido utilizada en el lenguaje común, mientras que praxis integra el vocabulario filosófico. En el presente texto se adoptan ambos vocablos, aunque se prefiera el segundo en virtud de su vinculación a la filosofía de la praxis(11):

En el lenguaje teórico, las palabras y expresiones funcionan como conceptos teóricos. Esto implica más precisamente que el sentido de las palabras está fijado en él, no por su uso corriente, sino por las relaciones existentes entre los conceptos teóricos en el interior de su sistema. ${ }^{(12)}$

En el caso de la salud colectiva, desde los textos seminales ${ }^{(13,14)}$ se entiende a la práctica de salud como una práctica social, no libre de las determinaciones económicas, políticas e ideológicas que componen la totalidad social. Por lo tanto, tal entendimiento va más allá del sentido común que, usualmente, 
considera a la práctica como algo opuesto a la teoría.

Así, en su crítica a la medicina preventiva, en tanto movimiento ideológico, Arouca ${ }^{(14)}$ propuso el desarrollo de una práctica política y una práctica teórica que posibiliten el abordaje de la cuestión sanitaria. De este modo, surgieron el proyecto de la Reforma Sanitaria Brasileña y el campo de la salud colectiva que, orgánicamente articulados en su emergencia ${ }^{(15)}$, presentaron desarrollos diferenciados, con aproximaciones y distanciamientos en diferentes coyunturas ${ }^{(16,17)}$. Si se admite que no hay una práctica en general, sino distintas prácticas, cabe siempre examinar las diversas teorías que dan sustento a tales prácticas.

La opción por el marxismo en el presente texto, como filosofía antagónica al liberalismo $^{(18,19)}$, se deriva de sus contribuciones para la elaboración y crítica del proyecto de la Reforma Sanitaria Brasileña ${ }^{(20)}$. A partir de la filosofía de Marx es posible identificar diversas prácticas en todos los niveles de existencia social: la práctica económica, la práctica política, la práctica técnica y la práctica científica o teórica ${ }^{(21)}$.

Para superar el sentido común y el sentido utilitario incorporado a la palabra práctica, se recurre al análisis de algunos estudios básicos sobre praxis y dialéctica:

La praxis ocupa el lugar central de la filosofía que se concibe a sí misma no solo como interpretación del mundo, sino también como elemento del proceso de su transformación. Tal filosofía no es otra que el marxismo. ${ }^{(22)}$

La praxis supone un sujeto que se contrapone al objeto para cambiar la realidad, pero que puede, también, sujetarse, conforme a su etimología que viene de subjectus (sujetado):

Es una actividad que precisa de la teoría para, autocríticamente, proporcionar al sujeto el poder de fundamentar sus decisiones y superar sus errores e insuficiencias. ${ }^{(23)}$
En efecto, que Antonio Gramsci en sus escritos de la cárcel se refiriera al marxismo como filosofía de la praxis ${ }^{(24)}$ no fue solo debido a la represión del fascismo. Era, también, un modo de distinguirse del idealismo y del materialismo mecanicista ${ }^{(18)}$. Para él, la praxis constituye una categoría central vinculada a la acción transformadora de los hombres, sintéticamente definida como el encuentro de la acción con la teoría:

La praxis es el concepto central de la filosofía de Marx, lo que está más vivo en ella. Es la matriz de una concepción original de la historia, una concepción que, siendo materialista, reconoce el poder del sujeto de tomar iniciativas, hacer elecciones. Por eso, precisa de una ética. Depende de valores que le permitan comprometerse en proyectos de transformación del mundo, en la creación de un tipo mejor de sociedad, en un futuro por el cual valga la pena luchar. ${ }^{(23)}$

Esta unidad entre teoría y práctica debe ser vista como un proceso. No está dada desde el inicio. Para Gramsci esa unidad es construida por un "acto crítico", pasando por distintos momentos:

Esta dialéctica de la teoría y la práctica, ese perpetuo ajuste en la lucha [...] que expresa plenamente el pensamiento de Gramsci, no debe ser interpretada de manera empirista, pragmática [...] La teoría no duplica la práctica: sistematiza, rectifica, enuncia en su validez conceptual. En función de que la propia práctica, por ser inventiva, coloca cuestiones nuevas a la teoría. ${ }^{(25)}$

De ahí las palabras del poeta y revolucionario de Cabo Verde, Amílcar Cabral: "pensar para hacer y hacer para pensar mejor"(26).

Sin embargo, una revisión de la noción de praxis muestra que antecede al marxismo, y expresa distintas concepciones al interior de la filosofía y en diferentes momentos de la historia: consciencia de la praxis en la Grecia antigua, consciencia renacentista de praxis y 
consciencia burguesa de praxis productiva ${ }^{(22)}$. En esta revisión, es posible constatar las concepciones de praxis en Hegel, Feuerbach, Marx y Lenin, pero con la salvedad de que "toda praxis es actividad, pero no toda actividad es praxis"(22). Cabe entonces distinguir la praxis, en tanto forma de actividad específica, de otras tantas actividades, desde aquellas relativas a la consciencia hasta las vinculadas al trabajo humano o a la creación artística.

$\mathrm{Si}$ consideramos que la materia prima de la actividad puede variar, es posible reconocer diversas formas de praxis: a) la praxis productiva (proceso de trabajo); b) la praxis artística; c) la praxis experimental (investigación); d) la praxis política. En lo que se refiere a los distintos niveles pueden ser mencionadas: la praxis creadora, la praxis reiterativa (imitativa, burocratizada), la praxis reflexiva y la praxis espontánea. En este repertorio Vázquez no admite, aún, la práctica teórica antes referida: "Eso significa que el problema de determinar lo que es la praxis requiere delimitar más profundamente las relaciones entre teoría y práctica"(22). Esta preocupación de delimitar tales relaciones se encuentra presente desde la formulación de la propuesta y del proyecto de la Reforma Sanitaria Brasileña, así como en el inicio de su proceso ${ }^{(8)}$ y en períodos más recientes ${ }^{(27,28)}$.

Si la praxis presupone la existencia de un sujeto, pensar la praxis en la Reforma Sanitaria Brasileña exige problematizar los sujetos de la praxis y, para ello, cabe considerar, especialmente, la praxis creadora, ya que permite enfrentar nuevas necesidades y situaciones. Se trata de reconocer un proceso en el cual no se alcanza todo lo que constaba en el proyecto, es decir, los desafíos de la praxis ${ }^{(29)}$. De modo semejante a los "tormentos de la creación" reconocidos por los artistas, los sujetos de la praxis de la Reforma Sanitaria Brasileña se dan cuenta de los obstáculos y desafíos en su proceso, con la incertidumbre e indeterminación que esto implica.

A los fines de este artículo, cabe destacar, particularmente, los trazos distintivos de una praxis creadora: a) unidad indisoluble, en el proceso práctico, de lo subjetivo y de lo objetivo; b) imprevisibilidad del proceso y del resultado; c) unidad e irrepetibilidad del producto $^{(22)}$. La comprensión de estas características exige, por otro lado, una praxis reflexiva en el sentido de indicar nuevas creaciones y de evaluar los motivos del fracaso. Por ende, para discutir el sujeto de la praxis en el proceso de la Reforma Sanitaria Brasileña cabe reflexionar sobre tales relaciones, en particular, la unidad entre la teoría y la práctica, pero reconociendo su distinción y autonomía relativa:

\begin{abstract}
La actividad teórica de los marxistas solo puede ser fecunda si no pierde sus nexos con la realidad que debe ser objeto de interpretación y transformación, y con la propia actividad práctica que es su fuente inagotable. ${ }^{(22)}$
\end{abstract}

Según este autor, es posible sistematizar la praxis a través de distintos momentos: crítica, proyecto, conocimiento de la realidad (situación objetiva) y acciones:

En primer lugar, como una crítica de lo existente por medio de la cual se expresa nuestra inconformidad con el mundo social que nos rodea [...] la crítica remite a un proyecto y transformación de la realidad presente [...]. De este modo, para que ese proyecto no sea un simple sueño, deseo o utopía pura, es necesario conocer la realidad que debe ser transformada [...] conocer también cual es el sujeto o los sujetos que pueden realizar esta transformación, así como los medios y caminos adecuados para esa realización [...]. Hay que contribuir a desencadenar una práctica, e inspirar acciones. ${ }^{(22)}$

Estos momentos sistematizados por el autor pueden ser tomados como referencia para analizar la praxis de la reforma. Así, se inicia con la crítica: a la educación médica, a la medicina preventiva, a la salud pública, a la epidemiología y a las ciencias sociales funcionalistas $^{(14,30)}$, a la medicina comunitaria ${ }^{(13)}$, a la situación de salud y a la privatización e ineficacia del sistema de salud brasileño ${ }^{(31)}$. 
Esta crítica remitía a un proyecto que, en el plano teórico, se tradujo en la emergencia de la medicina social y la salud colectiva ${ }^{(32)} y$, en el plano político, se reveló en la Reforma Sanitaria Brasileña y en la formulación del Sistema Único de Salud (SUS). Como tal proyecto no era un simple sueño fue necesario conocer la realidad a ser modificada, para lo cual se realizaron investigaciones sobre la práctica médica, el mercado de trabajo, las ideologías profesionales, las condiciones de salud y la intervención del Estado a través de la previsión social y las campañas

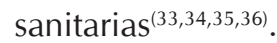

El conocimiento de los sujetos que podrían realizar tales transformaciones fue objeto de reflexión teórica ${ }^{(8,37)}$ para desencadenar una práctica, que orientara acciones. Estas acciones serían realizadas en la lucha política sociocomunitaria, junto a los movimientos sociales, en la estrategia legislativo-parlamentaria y en el ámbito técnico-institucional, en distintos niveles del sistema de salud: político, técnico-administrativo y técnico-operacional ${ }^{(38)}$.

Estos distintos momentos de la praxis de la Reforma Sanitaria Brasileña exigen una constante reanudación, en tanto praxis reflexiva, para admitir que, en cada situación concreta, un momento puede ser dominante con relación a los demás. Así, una determinada coyuntura puede exigir más la crítica que la elaboración de un proyecto. En otras situaciones, el conocimiento de la realidad puede preceder a la realización de acciones. Esta perspectiva dialéctica se hace necesaria para evitar una comprensión de los momentos como si fuesen etapas lineales.

A pesar de las fértiles pistas delineadas por Vázquez ${ }^{(22)}$, algunas objeciones han sido hechas sobre su estudio, tal vez, por no unir la praxis a la dialéctica:

Si la teoría y la praxis no se las vinculara a la dialéctica, pierden su principio de inteligibilidad, y su justificación solo podría ser hecha en términos de empirismo y pragmatismo. Por eso, es esencial que se muestre la dialecticidad de la praxis y de la teoría. Así, teoría y praxis encuentran su principio de legitimación dentro de la dialéctica, por la dialéctica, y concomitantemente la posición del hombre en tanto pensamiento y acción. ${ }^{(39)}$

Esta observación es fundamental para el trabajo teórico propuesto en este artículo, ya que se parte de la noción de "portadores de la antítesis"(10), vinculada a la dialéctica, para desarrollar los conceptos de sujeto de la praxis y sujetos de la antítesis.

\section{DE "PORTADORES" A SUJETOS DE LA ANTIITESIS}

En este tópico se procura realizar un trabajo de transformación de una noción ("portadores de la antítesis"), y aunque esté inspirada en una teoría determinada, en un concepto teórico, supone dos operaciones conjuntas: "la rectificación crítica de la antigua forma y la producción de la nueva, en un solo y mismo proceso"(12).

La transformación de una noción en un concepto mediante un trabajo teórico fue reconocida como una práctica teórica ${ }^{(14)}$ y puede ser ejercitada con relación a los "portadores de la antítesis". Este concepto, en estado práctico, surgió como un desdoblamiento analítico de la revolución pasiva brasileña al ser señalado, en ciertas coyunturas, como un actor potencialmente capaz de asegurar un carácter menos conservador al desenlace del proceso de revoluciónrestauración. En la coyuntura que propició la Ilamada Revolución del 30, el Partido Comunista Brasileño (PCB) fue identificado por Vianna ${ }^{(10)}$ como "portador de la antítesis".

En esta perspectiva, si la Reforma Sanitaria Brasileña fuera entendida como un proceso (abierto), cabría identificar a los "portadores de la antítesis" capaces de alterar la conservación-transformación en beneficio del segundo elemento de este binomio. Sin embargo, el término portador sugiere algo que carga o conduce alguna cosa, y puede inducir la idea de algo episódico, accidental, espontáneo o circunstancial. Aun así, esta 
noción fue utilizada para explicar el devenir de la Reforma Sanitaria Brasileña ${ }^{(5),}$ aunque posteriormente se haya adoptado la expresión sujeto de la antítesis ${ }^{(40)}$.

En el caso de la praxis, sin embargo, cabría pensar en algo intencional para permitir la formación o la constitución. El concepto de sujeto, tal como lo ha formulado Testa ${ }^{(41)}$, permite considerar la condición "potencial" y la situación de "constituido", como se presentará a continuación. Por lo tanto, el trabajo teórico sistematizado en este tópico indica las posibilidades de constitución de sujetos de la antítesis, que se distinguen de los sujetos de la praxis.

En este caso, si la praxis es praxis del sujeto, cabe en cada situación concreta identificar los sujetos de la praxis. Y, para la filosofía de la praxis el sujeto privilegiado no era un sujeto cualquiera, mucho menos un sujeto sujetado. El sujeto de la praxis era entendido como la clase obrera, en cuanto sujeto revolucionario, en la medida en que pudiera avanzar de la condición de "clase en sí" y alcanzar la condición de "clase para sí", y siempre y cuando, en la construcción de la hegemonía ${ }^{(42)}$, pasara del momento corporativo al momento ético-político.

Al desarrollar la filosofía de la praxis, Gramsci $^{(11,42)}$ trae cuestiones que van más allá del protagonismo de los sujetos. De este modo, cuando se piensa la praxis para establecer compromisos con las fuerzas potencialmente interesadas en el cambio de una situación -los sujetos de la praxis- algunas distinciones merecen ser destacadas entre el "plano del pensamiento que piensa la praxis [y] el plano de la propia praxis"(39).

En la actualidad, otros sujetos de la praxis podrían ser identificados, independientemente de la polémica relativa a la centralidad o no de la contradicción capitaltrabajo $^{(43)}$. Así, las reflexiones sobre sujetos sociales en la salud colectiva y, en particular, en la Reforma Sanitaria Brasileña, pueden indicar nuevos caminos para el enfrentamiento de los desafíos de la praxis.

Desde esta perspectiva, la constitución de un sujeto social supone la superación de su condición de individuo, cuando incorpora una ideología y la posibilidad de tornarse un actor social, en la medida en que sea capaz de incluir temas en la agenda del Estado ${ }^{(44)}$. Su intencionalidad, analizando concretamente las circunstancias, podría aguzar la consciencia crítica, estimular la movilización, construir la organización y buscar la efectividad de la intervención, como sujeto transformador ${ }^{(45)}$.

\section{LA CONSTITUCIÓN DE SUJETOS DE LA ANTÍTESIS PARA LA REFORMA SANITARIA BRASILEÑA}

La obra del pensador argentino Mario Testa es fundamental para la formación de sujetos, ante el desafío de pensar y actuar en situaciones en las que las condiciones para la transformación aún no están dadas ${ }^{(46)}$. De ahí el énfasis concedido por este autor a la constitución de sujetos sociales capaces de contribuir a la creación de esas condiciones, considerando las circunstancias históricas. Según este pensador, no todos los individuos traen en su historia de vida una actitud crítica. Esta depende de su experiencia personal y de las relaciones sociales a que ha estado sometido. Sin embargo, es posible admitir usos positivos de las contradicciones y conflictos producidos en la sociedad, en el sentido de desarrollar una aptitud crítica con vistas a la elaboración de un pensamiento estratégico que fundamente la praxis. Mientras la actitud crítica presenta una dimensión subjetiva y depende de la historia personal, la aptitud crítica tiene una dimensión objetiva y puede ser desarrollada, o no, por las organizaciones ${ }^{(45)}$.

A partir del cruce entre las categorías actitud crítica (presente o ausente) y aptitud crítica (presente o ausente) se identifican cuatro posibilidades de constitución de sujetos: a) seguidores pasivos, cuando los sujetos no tienen una actitud crítica ni encuentran oportunidades de desarrollo de una aptitud crítica en las organizaciones; b) funcionarios de gobierno, cuando no presentan una actitud crítica, pero desarrollan una aptitud crítica; c) 
sujetos transformadores cuando logran realizar el encuentro entre actitud crítica con la aptitud crítica; d) oposición estéril en las situaciones en las que el sujeto posee una actitud crítica, pero las organizaciones no contribuyen al desarrollo de una aptitud crítica, lo que reduce su eficacia política ${ }^{(45)}$.

El pensamiento que inspira esta articulación de conceptos apuesta a la constitución de sujetos transformadores y de trabajadores públicos capaces de aprovechar las contradicciones y conflictos presentes en diversas situaciones, para crear las condiciones para el desarrollo de proyectos de apertura, de avance y consolidación, considerando los tiempos técnico y político en los cuales se desarrollan las acciones ${ }^{(44,47)}$. En esta perspectiva se considera el pasaje de un sujeto potencial a un sujeto constituido en distintos niveles: individual, comunitario, institucional, político y estatal. Así, un sujeto potencial puede atravesar todos esos niveles sin pasar por un proceso de constitución, y presentarse apenas como individuo, masa, funcionario, consumidor, votante o población. $\mathrm{O}$ bien, un individuo puede transformarse en sujeto (portador de una ideología determinada) y, desde el nivel comunitario, evolucionar hacia una agrupación; desde el nivel institucional, hacia un analizador de la organización; desde el nivel político, hacia un militante; $y$, desde el nivel estatal, hacia un actor social ${ }^{(41,45)}$.

La posibilidad de que un sujeto potencial alcance la categoría de analizador, militante o actor social estaría presente hasta el nivel institucional. En los niveles político y estatal, ya no existiría, según Testa, la posibilidad de que el sujeto potencial se transforme en sujeto constituido ${ }^{(45)}$.

A partir de este referencial se pueden admitir a trabajadores de salud e integrantes del movimiento sanitario brasileño (sujetos individuales y colectivos) como sujetos de la praxis, pero esto no significa que representen, necesariamente, a sujetos de la antítesis. Estos tendrían que ser identificados, dialécticamente, por la negación de la tesis y por la radicalización del cambio en detrimento de la conservación.

\section{Sujetos de la antítesis en la revolución pasiva}

No obstante el jacobinismo de algunos autores y actores, ha predominado en Brasil la revolución pasiva, en la que la dialéctica del "conservar-cambiando" continúa imperando. De ahí la alternativa pensada para el actor en su intervención sobre la realidad: conocer las circunstancias y traducir la revolución pasiva en una guerra de posición, de tal modo que su acción se imponga "en un contexto que pretende su abdicación o su expulsión”(10).

Incluso las organizaciones de la sociedad civil identificadas con las protestas de los "de abajo" parecen contribuir con la conservación cuando limitan su actuación a reformas puntuales:

Las luchas de las minorías, por acceso a la tierra, vivienda, salud, educación, empleo, se hipertrofian en un torbellino de demandas fragmentadas, fácilmente despolitizadas y burocratizadas por el propio Estado, situándose en aquello que Gramsci denomina "pequeña política", que engloba cuestiones parciales $y$ cotidianas y que, necesariamente, debe vincularse a la "gran política" para crear nuevas relaciones. ${ }^{(48)}$

Por lo tanto, otro gran desafío de los sujetos de la antítesis es apostar a la "gran política", aunque atentos a los movimientos de la "pequeña política"(49), sea en el parlamento, sea en el ejecutivo, sea en los intersticios burocráticos y sociocomunitarios.

Ante las interpretaciones positiva y negativa de la revolución pasiva, identificadas en la obra de Gramsci, el uso de este concepto en el análisis del proceso de la Reforma Sanitaria Brasileña y el recurso a la categoría sujeto de la antítesis en la praxis política imponen un examen de la actuación del actor ante la realidad y los hechos. De esta actuación dependería el sentido más progresista o conservador, en cuanto resultado de ese proceso.

Sin embargo, la noción original de "portadores de la antítesis"(10) fue concebida desde la 
perspectiva positiva de la revolución pasiva en determinadas situaciones históricas, y representaría al actor capaz de examinar concretamente la realidad y de intervenir más allá del protagonismo de los hechos, evitando la tendencia regresiva del proceso. Pero los modos de actuación de ese actor no parecen dados a priori, ni son suficientemente elaborados en la obra del filósofo de la praxis. Si en algunos momentos de las notas de los Cuadernos de la cárcel se destaca cierto tenor jacobino, en otros se resalta el realismo político que debería orientar la actuación del actor. El fragmento que sigue, a pesar de su longitud, es útil para ilustrar esta aparente ambigüedad:

Si Mazzini, dice Gramsci, tuviera conciencia de su posición y del papel que le correspondía, así como de la posición y del papel de Cavour, es decir, "si hubiera sido un político realista y no un apóstol iluminado", tal vez el Estado italiano estuviese "constituido sobre bases menos atrasadas y más modernas". El Risorgimento sería un proceso de revolución pasiva en que el protagonismo de los "hechos" sobrepasó al actor que podría representar las expectativas populares, por falta de realismo político de éste, y, en ese sentido, debería ser considerado como ejemplar para la formulación de nuevas cuestiones "para el arte y la ciencia política" (Q.,1767). Si Mazzini supiera, es decir, si tuviera una concepción realista de su circunstancia - esta parece ser la lección general a ser extraída del Risorgimento -, el actor habría sido activo en la revolución pasiva, y podría haber ampliado e intensificado las modificaciones moleculares en la estructura de la correlación de fuerzas, que, a su vez, se conviertan en matrices de nuevas modificaciones (Q., $1767)^{(10)}$.

En realidad, la ambigüedad referida ilustra el gran desafío del arte y de la ciencia política para orientar la práctica: en qué medida la intuición política ante las circunstancias estimula el avance (determinación) o si ella supone el análisis concreto de la situación concreta y, en consecuencia, un cierto realismo ante la apreciación de las fuerzas del actor ante los adversarios (condicionamiento). El voluntarismo presente en situaciones en las cuales el análisis de viabilidad no apunta a posibilidades de éxito parece ilustrar la tenue distinción entre política y aventura. Así, al destacar las "transformaciones moleculares" en comparación al "momento explosivo" del tipo jacobino, Gramsci parece rechazar la condena de la reforma "como una heterodoxia revisionista"

Esta interpretación del concepto indicaba que la revolución pasiva podría ser más conservadora o progresista dependiendo de la acción del actor sobre los hechos y que tales posibilidades siguen siendo relevantes no solo para el análisis político y para los estudios históricos sino, sobre todo, para orientar la praxis.

Frente a las reflexiones gramscianas y su comprensión de la dialéctica, Vianna ${ }^{(10)}$ proporciona una creativa contribución teórica, apostando a una voluntad popular autónoma en la defensa de una democratización permanente y a la "convocatoria de la izquierda brasileña para las tareas de dirección de la revolución pasiva en el país"(50). Sin embargo, en esta obra el autor presenta ciertas advertencias y algunas posibilidades:

El riesgo de la disociación entre actor y "hechos", por falta, en él, de criterios para una adecuada evaluación de su situación, está en que la revolución pasiva se instituya como un proceso en que la transformación esté siempre limitada por los avatares de la conservación, obligando al mundo a una permanente reiteración desencantada del orden establecido. Continuar reflexionando sobre ella, en contextos, como el nuestro, históricamente dominados por su lógica, es una forma de movilizar el tipo de acción que permita a la dinámica del cambio sobrepasar a la de la conservación. ${ }^{(10)}$ 
En el caso brasileño algunas de estas posibilidades fueron identificadas en la modernización de la Revolución del 30 $0^{(10,51)}$. Estas posibilidades también se observaron en el nuevo sindicalismo del $A B C$ paulista (cordón industrial de San Pablo), en la creación del Partido de los Trabajadores (PT) y en la sucesión presidencial de $1989^{(50)}$. Sin embargo, muchos temas y preguntas permanecen abiertos y merecen reflexión y debates:

\section{¿A quién elegir como sujeto de la trans- formación socialista? ¿A los trabajadores o a los "excluidos"? ¿Cómo viabilizar la transformación? ¿Con o sin par- tidos? ¿Con qué modelo de partido? ¿Asignando qué papel al Estado? ¿A partir de qué noción de democracia? ${ }^{\text {(52) }}$}

Estas preguntas planteadas a fines del siglo pasado aún tienen vigencia en la actualidad, sobre todo en la compleja coyuntura brasileña a partir de 2013, aunque muchos hayan renegado del socialismo y otros, incluso, de la democracia.

A diferencia del movimiento sanitario cuya estrategia viene privilegiando una actuación preponderante en el ámbito del Estado, el Movimiento de los Trabajadores Rurales sin Tierra (MST) ha priorizado la formación, movilización, organización y luchas de ocupación, sin adoptar una concepción inocente del Derecho ${ }^{(53)}$. A pesar de reconocer los avances y la potencialidad de los "sin-tierra" cuando se liberan de los lazos de dependencia de los señores de la tierra y se articulan en las redes de la pastoral de la Iglesia Católica, alterando la geografía política del país, el autor advierte:

La condición, sin embargo, para la continuidad y profundización de ese movimiento molecular está en el "criterio de interpretación" - entender que la garantía del avance de la democratización social está en la ampliación de la democracia política, y no en una política de "apóstoles iluminados". ${ }^{(10)}$

Este criterio de interpretación podría ser utilizado para el análisis de la Reforma
Sanitaria Brasileña, mediante la adopción del concepto de sujetos de la antítesis y el empeño en su constitución para que sean capaces de radicalizar la democracia, pero sin la arrogancia y los equívocos de los apóstoles iluminados.

\section{COMENTARIOS FINALES}

Las reflexiones teóricas elaboradas en el presente estudio, a partir de la obra de Antonio Gramsci y de autores identificados con su pensamiento, posibilitan pensar la constitución de sujetos históricamente activos y organizados en busca de la conquista de la hegemonía, especialmente en el ámbito de la sociedad civil. En este sentido, la distinción entre sujetos de la praxis y sujetos de la antítesis se vuelve pertinente, sobre todo desde la perspectiva de redirigir la revolución pasiva con vistas al polo de la transformación.

Admitiendo la hipótesis de que el proceso de la Reforma Sanitaria Brasileña expresa o reproduce una revolución pasiva, el trabajo teórico realizado a partir de la noción de "portador de la antítesis" podría fundamentar nuevas intervenciones para el avance de esa reforma social. En efecto, "la realidad, en su totalidad, no se reduce a lo 'real', 'a lo que es' sino que abarca todas las virtualidades que se gestan en su interior" ${ }^{(54)}$. De este modo, la vitalidad del proceso de la Reforma Sanitaria Brasileña permite pensar la formación de sujetos de la praxis, así como la identificación de espacios virtuales para la constitución de sujetos de la antítesis que los transformen en espacios reales por vía de la praxis.

La investigación hermenéutica sobre la obra de Mario Testa ${ }^{(55)}$, además de destacar las dimensiones del poder y las relaciones entre el Estado, los propósitos del gobierno, las organizaciones, y la constitución de los sujetos y la historia, recupera la centralidad de la crítica y de la praxis, reafirmando la conclusión de que tal contribución continua siendo imprescindible para el pensar y el actuar estratégicos en salud en sus relaciones con la totalidad social(56) 
La distinción entre el plano del pensamiento (estratégico) y el plano de la praxis (acción estratégica), aunque metódica y no orgánica $^{(42)}$, parece relevante para que se considere la especificidad de la actuación del pensador, científico o filósofo, así como el tipo de cálculo, actividad o astucia del político. El distanciamiento crítico proporcionado por la reflexión teórica puede contribuir al análisis político en salud y vislumbrar la potencia de una praxis que supere el transformismo y el carácter conservador de la revolución pasiva en la Reforma Sanitaria Brasileña.

\section{REFERENCIAS BIBLIOGRÁFICAS}

1. Almeida CM. Reforma de sistemas de servicios de salud y equidad en América Latina y el Caribe: algunas lecciones de los años 80 y 90. Cadernos de Saúde Pública. 2002;18(4):905-925.

2. Labra ME. La reinvención neoliberal de la inequidad en Chile: El caso de la salud. Cadernos de Saúde Pública. 2002;18(4):1041-1052.

3. Gakidou E, Lozano R, González-Pier E, AbbottKlafter J, Barofsky JT, Bryson-Cahn C, Feehan DM, Lee DK, Hernández-Llamas H, Murray CJL. Evaluación del impacto de la reforma mexicana de salud 2001-2006: un informe inicial. Salud Pública de México. 2007;49(Supl 1):S88-S109.

4. Mendes EV. Os grandes dilemas do SUS. Salvador: Casa da Qualidade; 2001.

5. Paim JS. Reforma Sanitária Brasileira: contribuição para a compreensão e crítica. Salvador: EDUFBA; 2008.

6. Oliveira JA. Para uma teoria da Reforma Sanitária: "democracia progressiva" e políticas sociais. Saúde em Debate. 1988;(20):85-93.

7. Gallo E. Razão e planejamento: algumas indicações críticas para uma práxis emancipadora. [Dissertação mestrado]. Rio de Janeiro: Escola Nacional de Saúde Pública, Fundação Oswaldo Cruz; 1991.

8. Teixeira SF. (org.). Reforma Sanitária em busca de uma teoria. Rio de Janeiro: Abrasco; 1989.

9. Gramsci A. Cadernos do cárcere. Rio de Janeiro: Civilização Brasileira; 2000.

10. Vianna LW. A revolução passiva: iberismo e americanismo no Brasil. 2a ed. Rio de Janeiro: Revan; 2004.

11. Gramsci A. Concepção dialética da história. Rio de Janeiro: Editora Civilização Brasileira; 1966.
12. Althusser L. Sobre o trabalho teórico. Lisboa: Editorial Presença; 1978.

13. Donnangelo MCF. Saúde e sociedade. São Paulo: Duas Cidades; 1976.

14. Arouca S. El dilema preventivista: contribuciones a la comprensión y crítica de la Medicina Preventiva. Buenos Aires: Lugar Editorial; 2008.

15. Paim JS. Del "dilema preventivista" a la Saúde Colectiva. In: Arouca S. El dilema preventivista: contribuciones a la comprensión y crítica de la medicina preventiva. Buenos Aires: Lugar Editorial; 2008. p.145-149.

16. Paim JS. Desafíos para la salud colectiva en el siglo XXI. Buenos Aires: Lugar Editorial; 2011.

17. Vieira-da-Silva ML, Paim JS, Schraiber LB. O que é Saúde Coletiva. In: Paim JS, Almeida-Filho N. Saúde Coletiva: Teoria e Prática. Rio de Janeiro: MedBook, 2014. p. 3-12.

18. Losurdo D. Gramsci, do liberalismo ao "comunismo crítico". Rio de Janeiro: Revan; 2006.

19. Dias EF. Política brasileira: embate de projetos hegemônicos. São Paulo: Editora Instituto José Luís e Rosa Sundermann; 2006.

20. Paim JS. Contribuições do Marxismo para a Reforma Sanitária Brasileira. In: Pereira MC, Silva MDF. Recortes do pensamento marxista em saúde. Brasília: Dreams; 2006. p. 29-41.

21. Althusser L. Prefácio: de "El capital" a la filosofía de Marx: In: Althusser L. Balibar E. Para leer El Capital. 15a ed. México: Siglo Veintiuno Editores; 1977. p. 18-77.

22. Vázquez AS. Filosofia da práxis. Buenos Aires: CLACSO; 2007.

23. Konder L. Em torno de Marx. São Paulo: Boitempo; 2010.

24. Coutinho CN. (org.) O leitor de Gramsci: escritos escolhidos 1916-1935. Rio de Janeiro: Civilização Brasileira; 2011. 
25. Buci-Glucksmann C. Gramsci e o estado por uma teoria materialista da filosofia. Rio de Janeiro: Paz e Terra; 1980.

26. Cabral A. As palavras de ordem gerais. São Vicente, Cabo Verde: Direção Regional de São Vicente; 1969.

27. Santos RT. O fantasma da classe ausente: as tradições corporativas do sindicalismo e a crise de legitimação do SUS. [Tese doutorado]. Belo Horizonte: Departamento de Ciência Política; Faculdade de Filosofia e Ciências Humanas; Universidade Federal de Minas Gerais; 2014.

28. Silva THS. Força ou consenso: a Reforma Sanitária Brasileira entre o dilema reformista e o Minotauro da saúde. [Dissertação mestrado]. São Paulo: Faculdade de Saúde Pública, Universidade de São Paulo; 2016.

29. Paim JS. Collective Health and the challenges of practice. In: Pan American Health Organization. The crisis of public health: Reflections for the debate. Washington, DC: PAHO; 1992. p. 136-150.

30. Garcia JC. Apresentação: Juan César Garcia entrevista Juan César Garcia. In: Nunes ED. (org.). As ciências sociais em saúde na América Latina: Tendências e Perspectivas. Brasília: OPAS; 1985.

31. Guimarães R. Saúde e medicina no Brasil: contribuição para um debate. Rio de Janeiro: Edições Graal; 1978.

32. Donnangelo MCF. A Pesquisa na área de saúde coletiva no Brasil: a década de 70. In: Ensino da saúde pública, medicina preventiva e social no Brasil. Rio de Janeiro: ABRASCO, PEC/ ENSP; 1983. p. 17-35.

33. Donnangelo MCF. Medicina e sociedade: o médico e seu mercado de trabalho. São Paulo: Pioneira; 1975.

34. Luz MT. As instituições médicas no Brasil: Instituição e estratégia de hegemonia. Rio de Janeiro: Graal; 1979.

35. Braga JCS, Goes de Paula S. Saúde e Previdência: Estudo de política social. São Paulo: CEBES-HUCITEC; 1981.

36. Oliveira JAA, Teixeira SMF. (Im)previdência social: 60 anos de história da previdência no Brasil. Petrópolis: Vozes; 1985.

37. Arouca AS. Apresentação (contracapa). In: Teixeira SF. (org.). Reforma Sanitária em busca de uma teoria. São Paulo: Cortez; 1989.
38. Paim JS. Reforma Sanitária Brasileira: avanços, limites e perspectivas. In: Matta, GC, Lima JCF. (org.). Estado, sociedade e formação profissional em saúde: contradições e desafios em 20 anos de SUS. Rio de Janeiro: Editora Fiocruz, EPSJV; 2008. p. 91-122.

39. Bornheim GA. Dialética: teoria, práxis; ensaio para uma crítica da fundamentação ontológica da dialética. Porto Alegre: Globo; 1983.

40. Paim JS. Reforma Sanitária Brasileira: eppur si muove. Cadernos de Saúde Pública. 2013;29(10): 1952-1953.

41. Testa M. Vida: Señas de Identidad (miradas al Espejo). Salud Colectiva. 2005;1(1):33-58.

42. Gramsci A. Maquiavel, a política e o Estado moderno. Rio de Janeiro: Civilização Brasileira; 1976.

43. Laclau E, Mouffe C. Hegemonía y estrategia socialista: Hacia una radicalización de la democracia. 3a ed. Buenos Aires: Fondo de Cultura Económica; 2010.

44. Testa M. Pensamento estratégico e lógica de programação (o caso da saúde). São Paulo: HUCITEC; 1995.

45. Testa M. Decidir en salud: ¿quién?, ¿cómo? y ¿por qué? Salud Colectiva. 2007;3(3):247-257.

46. Testa M, Paim JS. Memoria e Historia: diálogo entre Mario Testa y Jairnilson Silva Paim. Salud Colectiva. 2010;6(2):211-227.

47. Testa M. Pensar em saúde. Porto Alegre: Artes médicas, ABRASCO; 1992.

48. Simionatto I. O social e o político no pensamento de Gramsci. In: Aggio A. Gramsci, a vitalidade de um pensamento. São Paulo: Fundação Editora UNESP, 1998. p 37-64.

49. Coutinho CN. Gramsci. Porto Alegre: L \& PM; 1981.

50. Carvalho MAR. Prefácio: uma reflexão sobre a civilização brasileira. In: Vianna, LW. A revolução passiva: iberismo e americanismo no Brasil. 2a ed. Rio de Janeiro: Revan; 2004. p.7-37.

51. Coutinho $\mathrm{CN}$. As categorias de Gramsci e a realidade brasileira. In: Coutinho $\mathrm{CN}$, Nogueira MA. (org.). Gramsci e a América Latina. Rio de Janeiro: Paz e Terra; 1985. p.103-127.

52. Nogueira MA. Gramsci e os desafios de uma política democrática de esquerda. In: Aggio A. 
Gramsci, a vitalidade de um pensamento. São Paulo: Fundação Editora UNESP; 1998. p.65-102.

53. Faleiros VP, Silva JFS Vasconcellos LCF; Silveira RMG. A Construção do SUS: Histórias da Reforma Sanitária e do processo participativo. Brasília: Ministério da Saúde; 2006.

54. Semeraro G. Gramsci e a sociedade civil: cultura e educação para a democracia. Petrópolis: Vozes; 1999.
55. Federico L. Análise política em saúde: a contribuição do pensamento estratégico. Salvador: EDUFBA; 2015.

56. Paim JS. Posfácio. Análise política em saúde: um pensamento estratégico para a ação estratégica. In: Federico L. Análise política em saúde: a contribuição do pensamento estratégico. Salvador: EDUFBA; 2015. p.279-286.

\section{FORMA DE CITAR}

Paim JS. Reflexiones teóricas sobre sujetos de la praxis y sujetos de la antítesis para la Reforma Sanitaria Brasileña. Salud Colectiva. 2017;13(4):599-610. doi: 10.18294/sc.2017.1400

Recibido: 6 de abril de 2017 | Aprobado: 17 de agosto de 2017

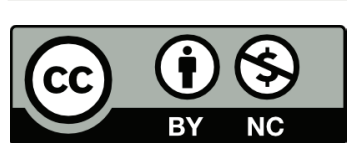

Este obra está bajo una licencia de Creative Commons Reconocimiento-NoComercial 4.0 Internacional. Reconocimiento - Permite copiar, distribuir y comunicar públicamente la obra. A cambio, se debe reconocer y citar al autor original. No Comercial - Esta obra no puede ser utilizada con finalidades comerciales, a menos que se obtenga el permiso. 